\title{
Premium Agricultural Measures for Hydraulic and Hydrogeological Risk Mitigation
}

\author{
Alexander Palummo \\ University of Florence, Florence, Tuscany, Italy
}

\begin{abstract}
This is the case with the sub-basins of the Caprio and the Teglia of the Alta Val di Magra, embankment walls — now often abandoned and camouflaged by vegetation - having a strong practical significance as well as symbolic and in terms of identity. Sometimes these embankment walls do not have a predominantly agricultural function, for example because they are used as property boundaries or to channel sludge, but in any case they retain a landscape value. For these reasons they deserve to be preserved and therefore also detected by GIS mapping, during extensive surveys in fluvial tracts.

With the analysis of land use changes it has been possible to identify the situations where landscape restoration was required (often former olive groves, vineyards and terraced orchards which have undergone km of forestation): the abandonment trend has not declined sufficiently and if the neglect of walls does not stop, there will be a proportional increase in the exposure to the risk of hydrogeological instability in the areas involved.
\end{abstract}

Key words: river restoration, hydrogeological risk, land planning, geographic information system

\section{Introduction}

The stone works used for agricultural arrangements have, among other functions, that of stabilizing the land having a particularly marked slope and facilitating water management for irrigation purposes. The walls indirectly contribute to the containment and mitigation of hydrogeological instabilities and, in lowland areas, to the partial reduction of the danger of flooding, thus reducing the hydraulic risk [1]. And carrying out maintenance of these arrangements within the ancient relationship between local culture and agriculture makes it possible to preserve and restore the typical landscape and mitigate the disasters of a hydro-geomorphological nature [2].

\section{The River Restoration Method}

In the flood of 2011 some nineteenth-century

Corresponding author: Alexander Palummo, Ph.D., research areas/interests: river restoration (PE10+SH3 discipline by European Research Council-ERC). E-mail: alexander.palummo@unifi.it. agrarian arrangements have resisted better than the latest engineering works. It was one of the many opportunities to observe the function of hydraulic containment and the mitigation of hydrogeological instability performed by dry stone walls, agricultural arrangements which are often nineteenth-century and more stable than the latest engineering works [1]. In the Upper Val di Magra such works, traditionally called "more", are nineteenth-century embankment walls which have a great practical and symbolic value, as emblems of a strong cultural identity: a historical and landscape value to be preserved even if their maintenance does not always appear to be compatible with the needs and objectives of the conservation and the morphological recovery of the watercourse (for this purpose there is realized a cartography, realized by means of the photo-interpretation of orthophotos, of the walls in agricultural use detected in the area of the high sub-basin of the Caprio and, for the sub-basin area, of the Teglia stream). 


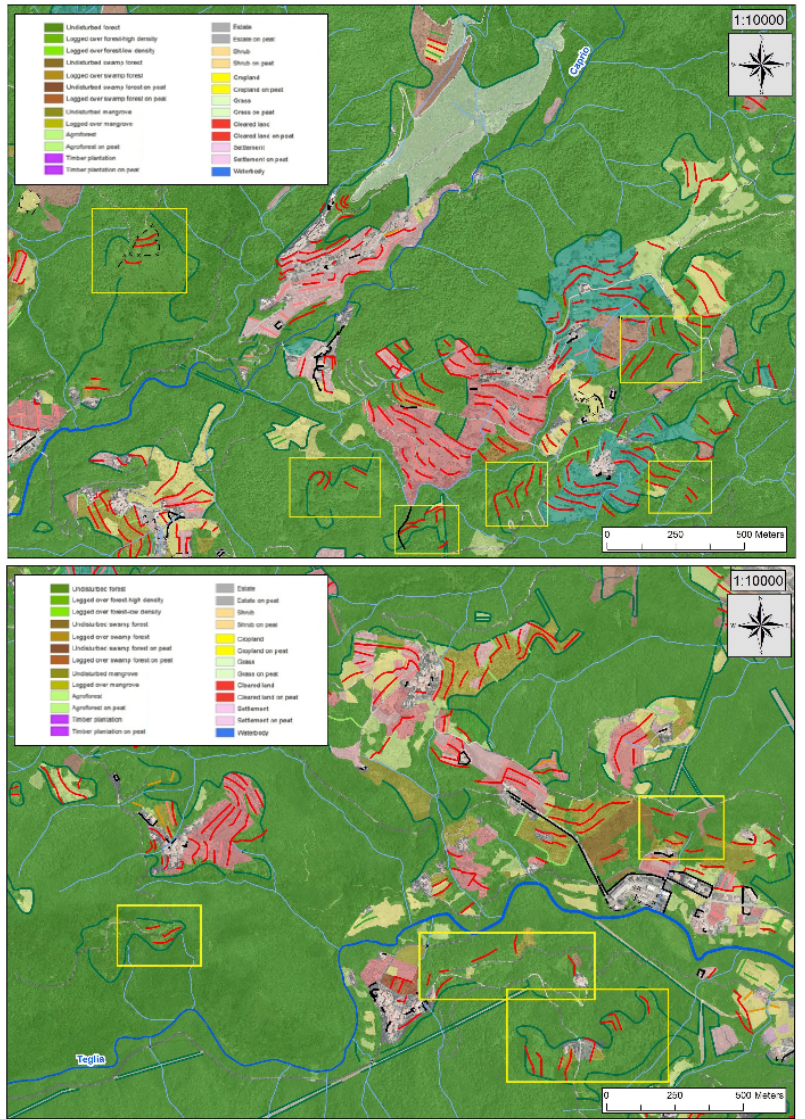

Fig. 1 Overlapping land uses and existing agricultural system in 1998. The abandoned drywalls are highlighted in yellow (Magra River Basin in Tuscany).

In other cases, these works do not have a predominantly agricultural function: for example, artisanal walls separating properties or having the function of channelling/containing the water near brooks and ditches [3]. Whether they serve to separate cultivated terraces or plots of arable land, or to manage waste water or for irrigation, they nevertheless have a landscape value which should be preserved, and for this reason they have also been detected during the inspections in the river stretches, through GIS mapping (even though neglected more and walls were barely recognizable, camouflaged in the vegetation).

The dynamics of the change in the coverage of the soils that require landscape restoration interventions have been highlighted (and where possible quantified) through the analysis of land use changes. The areas particularly subjected to forestation have subtracted several kilometres from the dry agricultural sites (mainly olive groves, terraced vineyards and orchards).

In the last decade, the neglect of the terraces in the two proposed sub-basins has decreased by only one fifth compared to the kilometres of neglected walls detected in the late 1990s. By projecting the rate of

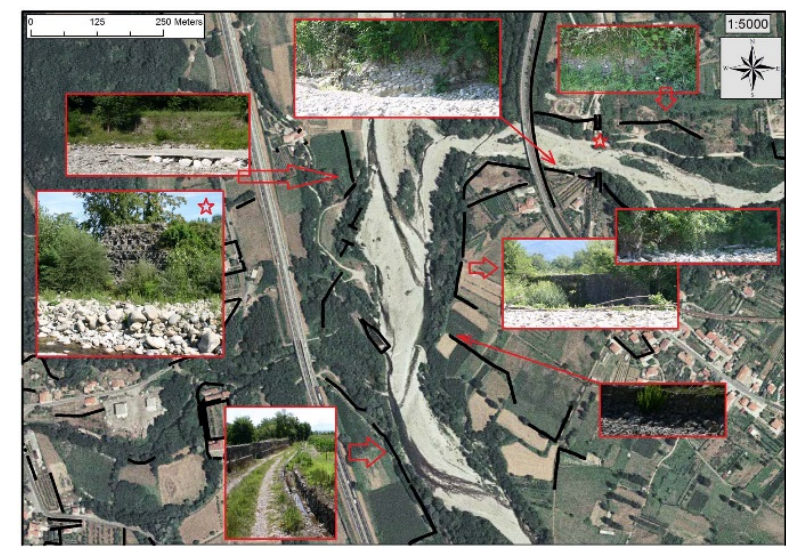

Fig. 2 Some nineteenth-century agrarian settlements have resisted better than the latest engineering works to the flood of 2011 (Magra River Basin in Tuscany).

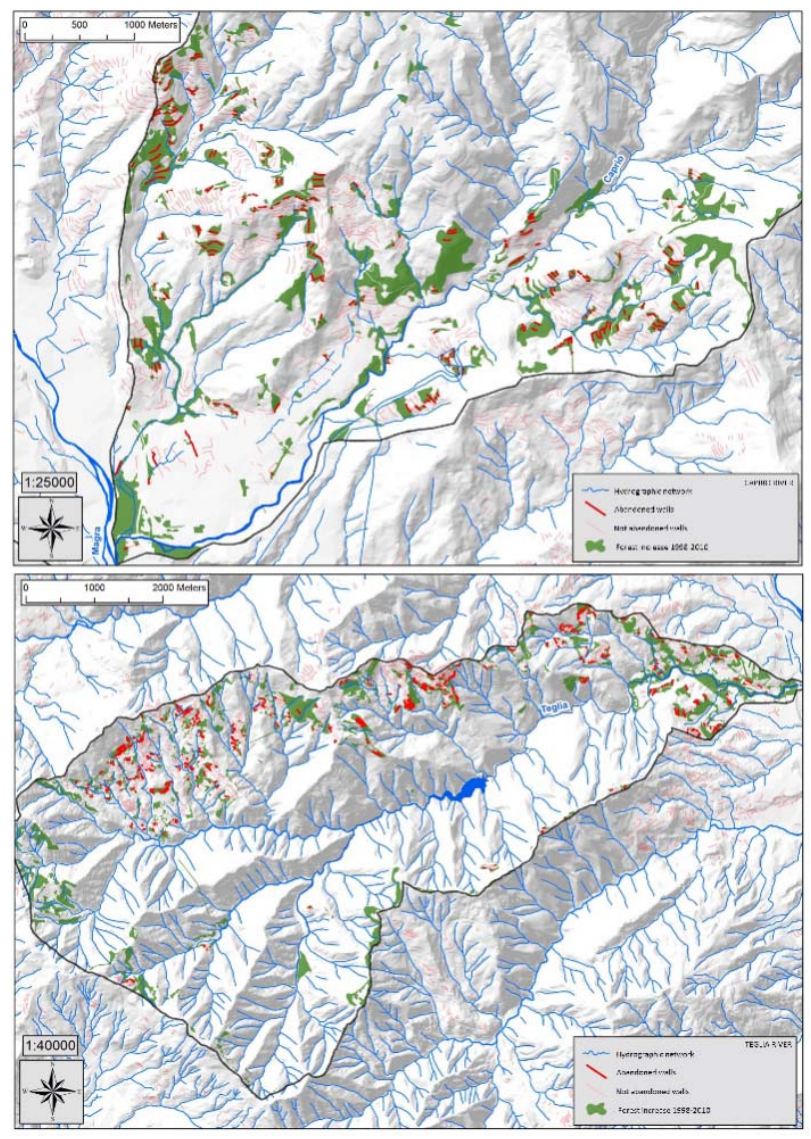

Fig. 3 Stone walls in areas subject to forestry in the sub-basin of Caprio and the sub-basin of Teglia (Magra River Basin in Tuscany). 
progress of neglect over the next fifty years, there is a real risk of witnessing the total disuse of more and walls and, with it, a dramatic increase in hydrogeological phenomena. Now, these estimates are fortunately only indicative because in order to have a greater predictive value, we should have data regarding the land-use change for at least the last fifty years, and such data are not currently available.

\section{Conclusion}

With the analysis of land use changes it has been possible to identify the situations where landscape restoration was required (often former olive groves, vineyards and terraced orchards which have undergone $\mathrm{km}$ of forestation): the abandonment trend has not declined sufficiently and if the neglect of walls does not stop, there will be a proportional increase in the exposure to the risk of hydrogeological instability in the areas involved.

\section{References}

[1] M. Rinaldi et al., IDRAIM: manuale tecnico operativo per la valutazione e il monitoraggio dello stato morfologico dei corsi d'acqua, ISPRA, Roma, 2011, p. 1.

[2] C. A. Garzonio, Il contributo delle analisi geologiche alla ricerca sul paesaggio e lo studio dei paesaggi geologici, Firenze University Press, Firenze, 2007.

[3] C. A. Garzonio, I caratteri idro-geo-morfologici dei bacini idrografici e dei sistemi morfogenetici, in: Daniela Poli, Regole e progetti per il paesaggio, Firenze University Press, Firenze, 2012. 